\title{
Differential diagnosis and management of a mural mass in the aortic arch
} \author{
Japan \\ From the ${ }^{\mathrm{a} D i v i s i o n}$ of Cardiovascular Surgery, Tohoku University Graduate School of Medicine, Seiryocho, \\ Aoba-ku, Sendai; and ${ }^{\mathrm{b}}$ Department of Cardiovascular Surgery, Hachinohe City Hospital, 1 Bishamontai, Tamu- \\ Received for publication Oct 21, 2016; revisions received Dec 5, 2016; accepted for publication Dec 18, 2016 \\ Address for reprints: Naoki Masaki, MD, Seiryocho, Aoba-ku, Sendai 980-8574, Japan (E-mail: n.masaki@med. \\ Cardiovasc \\ Copyright $(2017$ by The American Association for Thoracic Surgery
}

Naoki Masaki, MD, ${ }^{\mathrm{a}}$ Takashi Ogasawara, MD, PhD, ${ }^{\mathrm{b}}$ and Katsuo Matsuki, MD, PhD, ${ }^{\mathrm{b}}$ Sendai and Aomori,

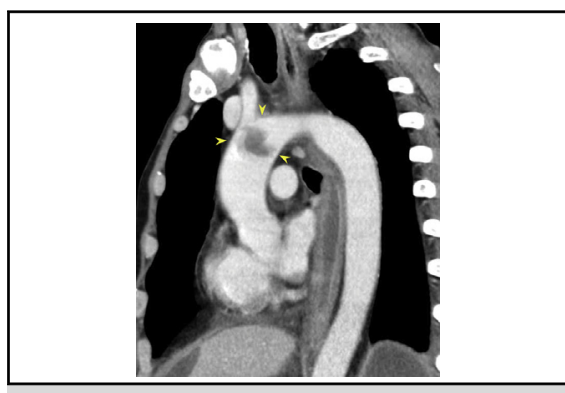

Mural masses are rare but important embolic sources for distal arteries.

Central Message

A mural mass in the aortic arch leads to potentially life-threatening embolic complications, and surgical treatment is favorable for this rare condition.

See Editorial Commentary page e85. endovascular stent graft. However, there is a lack of consensus regarding the management of these conditions, and this management is different from their diagnosis. We report 3 patients with intraluminal masses in the thoracic aorta, particularly in the aortic arch, and discuss the therapeutic management of this condition.

\section{CLINICAL SUMMARY}

The patients' details are shown in Table 1.

\section{Patient 1}

A 58-year-old man presented with abdominal pain. Computed tomography (CT) showed gastrointestinal perforation caused by sigmoid colon cancer, as well as a mural mass in the aortic arch (Figure 1, A). Emergency right hemicolectomy and Hartmann's operation were performed. The mural mass was diagnosed as a mural thrombus and treated conservatively with anticoagulants for 4 weeks. CT scans performed 4 weeks after initiating warfarin revealed that the mural mass had completely resolved, and there were no visible systemic emboli; therefore, we continued the conservative therapy (Figure 1,B).

\section{Patient 2}

A 73-year-old man was referred to our hospital for vertigo. Magnetic resonance imaging (MRI) revealed acute phase cerebral infarction. During the workup for embolic infarction, a stringy mural mass was detected in the aortic arch by transesophageal echocardiography. He was treated conservatively

diagnosis is important because these result in lifethreatening distal arterial embolisms, such as cerebral infarctumors such as angiosarcoma and leiomyosarcoma, ${ }^{3}$ but accurate diagnosis before treatment is difficult. Several therapeutic options are available, such as systemic tion. Diffential diagnoses include mural thrombosis ${ }^{1,2}$ or \section{(1)}


TABLE 1. Patient summary

\begin{tabular}{|c|c|c|c|c|c|c|c|c|c|}
\hline Case & Age (y) & Sex & $\begin{array}{l}\text { Reason of } \\
\text { detection }\end{array}$ & $\begin{array}{c}\text { Localization of } \\
\text { mass } \\
\end{array}$ & Therapy & Final diagnosis & $\begin{array}{c}\text { Underlying } \\
\text { diseases }\end{array}$ & $\begin{array}{c}\text { Follow-up } \\
(\mathbf{y})\end{array}$ & Result \\
\hline 1 & 58 & Male & Incidental (CT) & Aortic arch & Warfarin, aspirin & Thrombosis & Colon cancer & 1.8 & No recurrence \\
\hline 2 & 73 & Male & $\begin{array}{l}\text { Embolisms } \\
\text { (cerebral } \\
\text { infarction) }\end{array}$ & Aortic arch & $\begin{array}{l}\text { Warfarin and } \\
\text { aspirin, } \\
\text { resection }\end{array}$ & Thrombosis & None & 6.5 & No recurrence \\
\hline 3 & 53 & Male & $\begin{array}{l}\text { Embolisms } \\
\text { (cerebral } \\
\text { infarction and } \\
\text { renal infarction) }\end{array}$ & Aortic arch & $\begin{array}{l}\text { Warfarin and } \\
\text { aspirin, } \\
\text { resection }\end{array}$ & Leiomyosarcoma & Leiomyosarcoma & 1 & Died of metastasis \\
\hline
\end{tabular}

CT, Computed tomography.

\section{DISCUSSION}

An intraluminal mass in the thoracic aorta is a relatively uncommon condition, but it is an important source of emboli and is associated with a high complication rate. The most common differential diagnosis is mural thrombus, ${ }^{1}$ and the other rare diagnosis includes intraluminal tumor such as aortic sarcoma. ${ }^{4}$ It has been reported that positron emission tomography/CT is useful in differentiating these conditions, ${ }^{5}$ and that this imaging modality might be helpful in selecting the appropriate treatment strategy for patients with intraluminal aortic masses. If the mass were a mural thrombus, as is the most common diagnosis, some researchers favor conservative management with anticoagulation therapy, which usually leads to complete resolution without additional embolic events. ${ }^{6}$ However, previous reports suggest that primary anticoagulation therapy is associated with a higher risk of recurrence of thrombosis and complications compared with primary surgical management. ${ }^{2}$ Therefore, the optimal management of these patients is still controversial. In addition, these mural masses are commonly located in the descending or abdominal aorta $(54 \%-89 \%),{ }^{1-3}$ and their common sites of
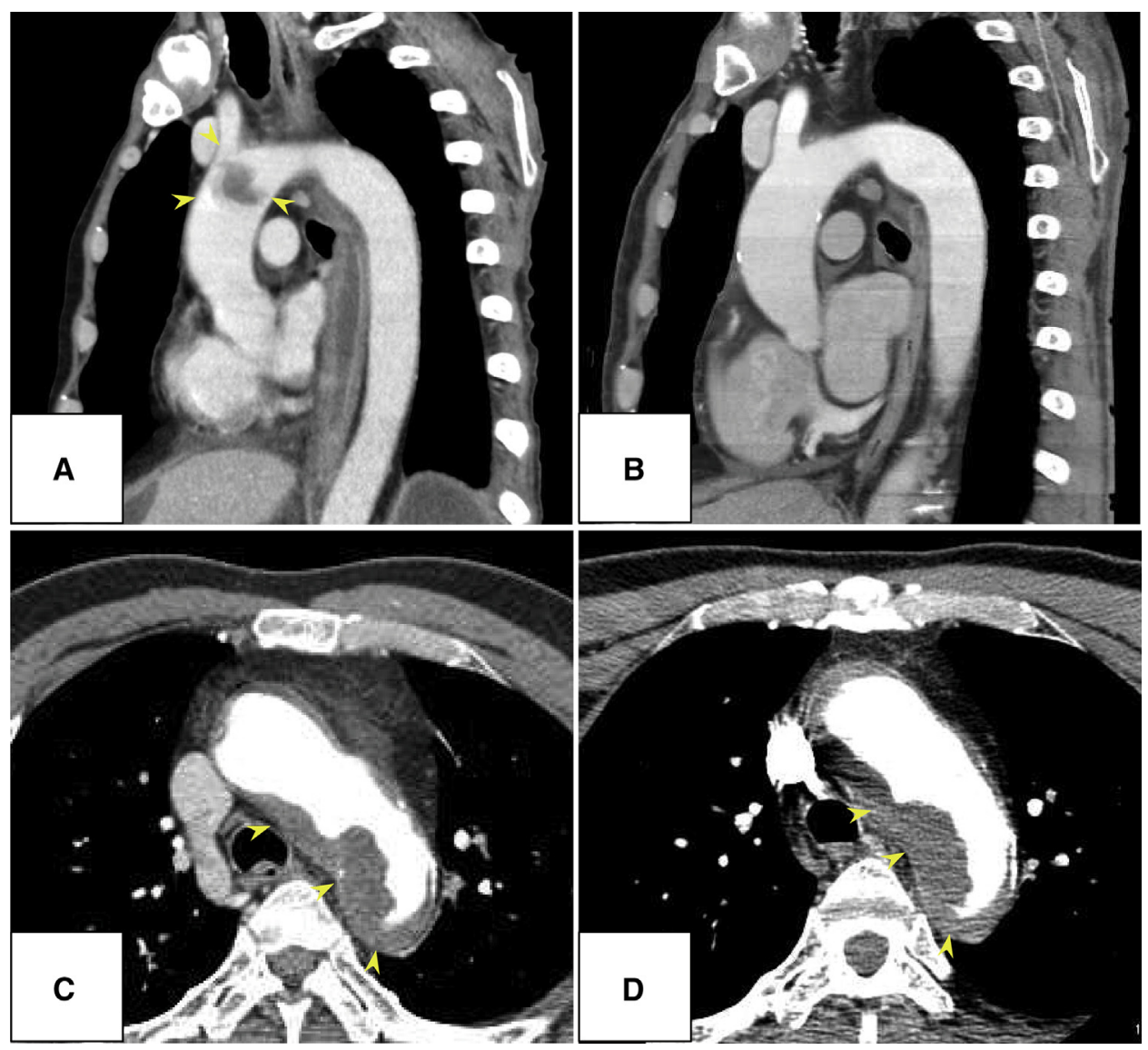

FIGURE 1. CT scans (A) before and (B) after conservative anticoagulation therapy in patient 1. The mural mass (arrowheads) in the aortic arch has completely resolved, indicating that it was a mural thrombus. CT in patient 3 shows (C) a mural mass (arrowheads) in the aortic arch (D), which persisted after 4 weeks of anticoagulation therapy. This mass was finally diagnosed as a leiomyosarcoma. 
embolism were located mainly in the renal and lowerextremity arteries. However, in patients in whom a mass is located within the aortic arch, as in our case series, potentially life-threatening cerebrovascular embolic complications could occur. In addition, mobile mural masses in the aortic arch may be a cause of recurrent cerebral embolization. ${ }^{7}$ Therefore, the therapeutic strategy for mural masses in the aortic arch should be considered more carefully, and surgical options may be more favorable.

Recent reports describe favorable early outcomes of endovascular repair for patients with mural thrombi or tumors. ${ }^{8}$ However, its long-term outcome has not been fully established, and its usefulness in the management of mural masses remains controversial. In addition, endovascular repair may be suitable for the treatment of patients with mural masses in the descending thoracic aorta. Masses in the aortic arch, as those in the present study, or masses in the visceral segment of the aorta may exclude this treatment option.

\section{CONCLUSIONS}

A mural mass in the aortic arch is rare, but early diagnosis and treatment are important to prevent life-threatening embolic complications. Differential diagnoses include mural tumor and thrombosis. We suggest that a primary surgical procedure is necessary in such cases.

\section{References}

1. Verma H, Meda N, Vora S, George RK, Tripathi RK. Contemporary management of symptomatic primary aortic mural thrombus. J Vasc Surg. 2014;60:1524-34.

2. Fayad ZY, Semaan E, Fahoum B, Briggs M, Tortolani A, D’Ayala M. Aortic mura thrombus in the normal or minimally atherosclerotic aorta. Ann Vasc Surg. 2013; 27:282-90.

3. Rusthoven CG, Liu AK, Bui MM, Schefter TE, Elias AD, Lu X, et al. Sarcomas of the aorta: a systematic review and pooled analysis of published reports. Ann Vasc Surg. 2014;28:515-25.

4. Mecklai A, Rosenzweig B, Applebaum R, Axel L, Grossi E, Chan A, et al. Intimal sarcoma in the aortic arch partially obstructing the aorta with metastasis to the brain. Tex Heart Inst J. 2014;41:433-6.

5. Nagai T, Tabata H, Uehata A. Primary sarcoma of pulmonary artery resembling large pulmonary thrombus: diagnostic utility of different imaging modalities. Eur Heart J. 2012;33:2271.

6. Laperche T, Laurian C, Roudaut R, Steg PG. Mobile thromboses of the aortic arch without aortic debris. A transesophageal echocardiographic finding associated with unexplained arterial embolism. The Filiale Echocardiographie de la Societe Francaise de Cardiologie. Circulation. 1997;96:288-94.

7. Lancaster G, Lovoulos CJ, Moussouttas M, Goldstein AH, Leifer D, Fayad PB et al. Aortic arch replacement for recurrent cerebral embolization. Ann Thorac Surg. 2002;73:291-4.

8. Morris ME, Galinanes EL, Nichols WK, Ross CB, Chauvupun J. Thoracic mural thrombi: a case series and literature review. Ann Vasc Surg. 2011;25 1140.e17-21. 